\title{
Fish Processing and Its Energy Dynamics in Zambia
}

\section{Ebenezer Miezah Kwofie', Emmanuella Ellis ${ }^{1}$, Sven Genschick ${ }^{2}$, Michael Ngadi ${ }^{1}$, Shakuntala Thilsted 2}

${ }^{1}$ Department of Bioresource Engineering, McGill University, Ste-Anne-de-Bellevue, QC, Canada

${ }^{2}$ WorldFish, Lusaka, Zambia

Email:michael.ngadi@mcgill.ca

How to cite this paper: Kwofie, E.M., Ellis, E., Genschick, S.., Ngadi, M. and Thilsted, S. (2019) Fish Processing and Its Energy Dynamics in Zambia. Journal of Sustainable Bioenergy Systems, 9, 44-63. https://doi.org/10.4236/jsbs.2019.92004

Received: November 16, 2018

Accepted: May 21, 2019

Published: May 24, 2019

Copyright $\odot 2019$ by author(s) and Scientific Research Publishing Inc. This work is licensed under the Creative Commons Attribution International License (CC BY 4.0).

http://creativecommons.org/licenses/by/4.0/

\begin{abstract}
This study presents field data and results on local fish processing, its energy supply, and consumption in the Northern Province of Zambia. The study also evaluates the impact of processing conditions on fish quality and cost for the different processing systems available in the selected communities. The result shows that fuelwood is the primary source of energy for fish processing used either in a modified three-stone fire (MTSF) system or a recently developed kiln. The charcoal smoking alternative had the least fuel consumption, yet was not considered as the preferred option due to the high cost of the fuel, a smaller quantity of fish processed per batch and longer processing time. The result also revealed that irrespective of the system used, the type of fish being processed and the pre-smoking drying time had a significant impact on the total energy consumption. Overall, the smoking kiln was found to increase the quantity of fish processed by five folds, reduce fuel use by $48 \%$ and reduce the overall smoking time per kilogram fish processed by $39 \%$. A relatively higher fish quality was obtained with the use of the smoking kiln in comparison with the MTSF and the charcoal smoking system. The use of the smoking kiln as a fish processing system is recommended because it improves the quality of the fish, can scale up fish processing due to its capacity and reduces energy use with its associated costs.
\end{abstract}

\section{Keywords}

Fish, Energy Dynamics, Fish Processing, Fuel Supply, Smoking Systems

\section{Introduction}

Agriculture is an important source of livelihood for the people of Zambia. 
Beyond the cultivation of food crops and the rearing of animals, the country has 15 million hectares of water in the form of rivers and lakes which is farmed for fish. Fishing, therefore, serves as a source of employment and livelihood for a vast number of individuals, with about 300,000 people along the chain serving as fish farmers (industrial operators or traditional fisher), traders and processors [1]. The agricultural sector's contribution to GDP is $18 \%$ out of which $3 \%$ can be attributed to the fisheries sector [1]. Fish is a protein source desired by the majority of people and even more importantly in the face of food and nutrition insecurity, improvement of its supply either through aquaculture or capture fisheries has the advantage of improving the nutrition of people. The demand for fish is higher than its production with an evidence of imports in the value of $\$ 1.9$ million [1].

The problem of fish demand unable to be met by fish supply could also be as a result of the losses prior to fish reaching the consumer. Due to the limited and inadequate storage and transport facilities, a greater percentage (65\%) of the fish is sun-dried, salted or smoked-dried before sold on the market for consumption. Fish processing and fuelwood supply are the main areas of employment associated with the fishery sector [1]. Modified methods such as freezing or canning used to increase the shelf life of fish may exist in most developing countries but may not be available within the fishing communities. Thus, traditional methods such as smoking and sun drying lend themselves as the most practical technique for fish processing. Certainly, these methods come with several challenges with respect to the environment and human health. The fuelwood systems and cookstoves have been found to cause respiratory diseases, death, burns, and scalds [2] [3]. Apart from injuries through physical contact with the stoves, inhalation of emissions from the burning solid fuels leads to serious health problems such as lung cancer, pneumonia, and heart diseases, coupled with the stress of carrying firewood over long distances [4]. Increasing demand for wood leads to a high rate of deforestation within communities which impacts the climate negatively [5]. The burning of wood releases pollutants such as carbon dioxide, carbon monoxide, hydrocarbons and other organic compounds into the environment [6].

Efficient solutions to enhance fish processing activities, reduce energy, health, and environmental cost, can only be designed and implemented based on a thorough evaluation and understanding of the current activities performed during fish processing and its impacts. This sets the pace for a better analysis of the challenges associated with fish processing and the strategies better fitted to solve them. There are currently few quantitative reports on fish processing energy requirements, the impact of processing activities on energy consumption and the challenges with respect to the use of different processing systems. In an effort to address this drawback, the study was set up: 1) to assess the local fish processing activities in the Northern Province of Zambia, 2) to estimate energy consumption and examine factors affecting energy use and, 3) to assess the impact of different fish processing systems on fish quality and processing cost. 


\section{Material and Methods}

\subsection{Study Location}

The study was conducted in two communities namely Ipusukilo and Ibale, located in Luwingu district, Northern Province of Zambia. The district has a human population estimated at 134,426 [7] over the surface area of $8892 \mathrm{~km}^{2}$. It lies between longitudes $30^{\circ} \mathrm{C}$ and $32^{\circ} \mathrm{C}$ East of the Greenwich Meridian and latitudes $9^{\circ} \mathrm{C}$ and $11^{\circ} \mathrm{C}$ South of the Equator and at an average altitude of $1500 \mathrm{~m}$ above sea level. The Ipusikilo community is part of the Luwingu main district agricultural camps within the Chulungoma block. Ibale, on the other hand, is part of the Nsombo camp in the Tungati block. These blocks were selected for the study based on their fishing and fish processing activities. Ipusukilo and Ibale are situated 2 and $72 \mathrm{~km}$, respectively, from the district capital. Figure 1 shows the map of the Luwingu district with the study areas shaded in red.

Major crops grown in the district include beans, cassava, groundnuts, finger millet, Bambara nuts, and maize. Major livestock kept includes goats, sheep, chickens, and pigs. Temperature varies across the year on the district with a warmer climate within the month of November to April and a fairly cold temperature from $8^{\circ} \mathrm{C}-22^{\circ} \mathrm{C}$ in the months of May and July. Temperatures range from $21^{\circ} \mathrm{C}$ to $24^{\circ} \mathrm{C}$ from August to October with humid and partial rainfall. The district lies in the high rainfall agro-ecological region of Zambia, with an average annual rainfall of $1200 \mathrm{~mm}$. There are several water resources, mainly rivers and forests which make up the districts' rich vegetation coupled with soil characterized by well-drained to moderately drained, deep strong brown friable fine loamy to clay soils. The climate and environment are found to be ideal for the production of many crops, particularly rice, livestock rearing and fish farming. Farming is an economic activity providing employment for $39.7 \%$ of the population in the district. Females make up about $70.5 \%$ of 53,408 farmers in the district [7].

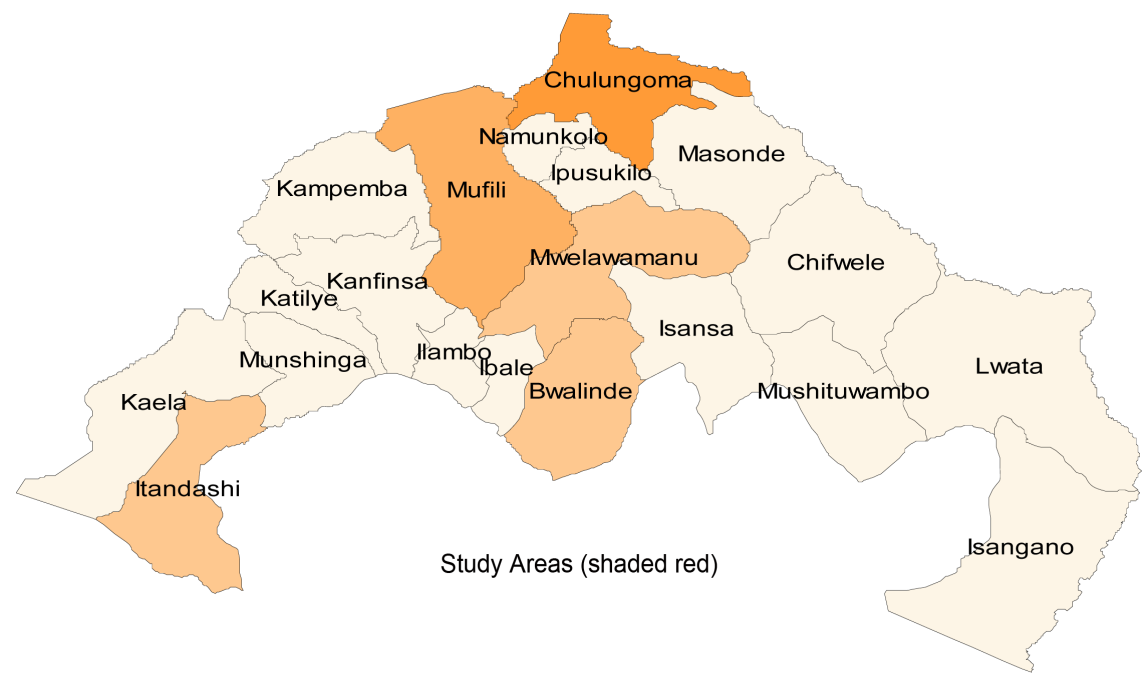

Figure 1. Map of Luwingu district showing the study areas (Ipusukilo and Ibale) in red. 


\subsection{Field Studies}

The study was undertaken from July to August 2017. During the visit to the selected communities, fish processors were interviewed, and observational data were collected. The data collected was to assess: 1) processing activities, equipment and energy supply, 2) factors influencing fish processing energy use, 3) cost of energy to fish processing. Local wood collections points, processing centers, and markets were visited for observational data. The energy supply data was collected from local wood collectors, charcoal sellers, as well as wood and charcoal users. To estimate energy use and factors influencing fuel consumption, measurements were taken on the various elements that are likely to influence fuel use. These elements included quantity of fish, smoking duration, wood species and sizes, and quantity of charcoal. The survey information collected during the visits are shown in Table 1.

\subsection{Energy Consumption Measurement}

Measurements of energy consumption were completed at the fish processing centers. Fish processing energy was defined as the amount of thermal energy supplied for smoking a known quantity of fish. The quantity of fish to be processed was weighed prior to the onset of processing using a $100 \mathrm{~kg}$ Camry two-dial platform scale-model FD100 (Zhongshan Camry Electronic Co. Ltd., China-Mainland) with a minimum capacity of $100 \mathrm{~g}$ and readability of $50 \mathrm{~g}$. Temperature was measured with a Patec Digital Instant Read LCD Screen Cooking Thermometer with a long stainless probe with a wide temperature

Table 1. Survey information.

\begin{tabular}{clll}
\hline \multicolumn{1}{c}{ Observation } & \multicolumn{1}{c}{ Processing Test } \\
\hline Description & $\begin{array}{l}\text { Researcher interviews fish processors, } \\
\text { wood collectors and marketers of processed fish }\end{array}$ & $\begin{array}{l}\text { Measurement of data at the initial through to the } \\
\text { final stages of the processing chain } \\
\text { Observation of session and recording of time } \\
\text { series of processors activities }\end{array}$ \\
Quantitative Data & - Cost of unprocessed and processed fish & Processing duration
\end{tabular}


measurement range of $-50^{\circ} \mathrm{C}\left(-58^{\circ} \mathrm{F}\right)$ to $300^{\circ} \mathrm{C}\left(572^{\circ} \mathrm{F}\right)$ and with $0.1^{\circ} \mathrm{F} /{ }^{\circ} \mathrm{C}$ resolution, $\pm 1.5^{\circ} \mathrm{F} / 0.8^{\circ} \mathrm{C}$ accuracy. Wood consumption was estimated as the difference between the initial and final weight of wood. The initial wood weight was the mass of wood planned to be used. The final wood weight on the other hand was the weight of unused wood, unburnt wood taken from the fire and the charcoal generated during the smoking. Similarly, charcoal consumption was the estimated as the difference between the initial and final weight of charcoal. Total distance traveled and time spent in a round trip for the wood collection was recorded with Etrex 10 Garmin GPS (Garmin International, Inc., Kansas, USA). This included time spent in exchanges between people collecting wood and farmers working on their farms.

\subsection{Statistical Analysis}

Statistical analyses were carried out on wood consumption, using linear regression models in the JMP software. Analysis of variance (ANOVA) was conducted, and significance of differences among different fish processing systems was separated using the Least Significant Difference (LSD) at a 5\% probability level. Comparison of means was done using the Turkey-Kramer HSD model.

\section{Results and Discussion}

\subsection{Material Supply for Fish Processing}

\subsubsection{Fish Supply}

The processing of fish as a small-scale business is seasonal in northern Zambia hence processors may switch to other activities when the fishing season is over. Limited capital to start processing activities and the unavailability of fish usually in the cold season, were cited as primary limiting factors to large-scale full-time fish processing. Fish processing activities are also limited during the raining season due to the difficulty in adequately drying fish before and after smoking. There is a nationwide ban on fishing from December to February which seeks to protect the breeding of commercially preferred species such as Tilapia which have peak breeding in the defined period. According to the processors, there is little to no activity during the ban period.

Several fish species are available in the study area; however, catfish and tilapia have become the dominant fish species processed in the communities. There are other species such as Milonge (Clarias theodorae), Matuku (Tilapia sparrmanii), and Mpende (Tilapia rendalli) which are also processed in the communities. Most of the processors are not directly involved in the fishing process but purchase fish from the market or directly from fishermen at the lake shore. The fish quantities are measured in plates, bowls or baskets and transported to the processing centres on foot. The average transport distance to processing centres are $20 \pm 5$ and $70 \pm 10 \mathrm{~km}$ from the market and lakeshore, respectively. A plate of fish cost about K7, a bowl of fresh fish usually cost K10 to K20 and a bucket cost $\mathrm{K} 50$ to $\mathrm{K} 100$. The variations in price depend on the size of the fish and the seller, either the fisherman or a fresh fish seller. 


\subsubsection{Fuel Supply}

Wood and charcoal are the primary source of fuel for fish processing and other domestic activities, though, charcoal is not used for commercial fish processing due to its cost. The processors usually collect firewood themselves for their activities from village wood collection points. Travel distance to the point of firewood collection and back including the time spent in gathering wood is about 90 min. Wood collected from the local collection points are transported by foot, with the wood carried on the head in bundles. A bundle weighs about 10 to 15 $\mathrm{kg}$ depending on the wood sizes and species and could be enough for processing between 2 to $3 \mathrm{~kg}$ of fish depending on type and size. The main types of wood collected and used in the area include Mpasa (Julbernardia globiflora), Chimpampa (Monotes africanus), Mulombwa (Pterocarpus angolensis), and Muombo (Brachystegia longifolia).

On a household scale, charcoal may be used for processing of fish. There are three primary stakeholders involved in the charcoal supply. Charcoal producers burn wood in a controlled low oxygen environment to obtain the product which is sold to households, thus doubling as wholesalers of the fuel. There are the charcoal retailers and users as other stakeholders of the chain. The charcoal producers/wholesalers transport charcoal from other villages and sell to retailers who are central suppliers to the fish processors. Retailers, on the other hand, can also travel the distance to purchase wood from wholesalers to sell. Fish processors travel a distance less than $5 \mathrm{~km}$ to purchase charcoal which is sold in sacks of about $25 \mathrm{~kg}$ at cost of about K25-30.

\subsection{Fish Processing Systems}

The basic processing setup includes a smoking system (including a stove and the smoking tray), drying tray and a descaling knife. The smoking systems available in the selected communities were a Modified Three-Stone Fire system (MTSF), Charcoal smoking system and a recently introduced smoking kiln. The drying tray is basically made up of a 24 in wooden frame with wire mesh fitted to it. The $0.36 \mathrm{~m}^{2}$ rectangular frame and can hold up to 20 pieces of large fish (Tilapia) and about 50 pieces of small fish (Milonge). During smoking, the wire mesh with the dried fish is placed directly unto the stove, with the fire and heat directly in contact with the wire and the fish.

\subsubsection{Modified Three-Stone Fire System}

The modified three-stone fire (MTSF) is the main smoking system used for processing fish both for domestic use and commercial purposes. The modification from the traditional TSF is the arrangement of the stones. In this case, the stones (cement blocks) are arranged opposite to each other in a rectangular pattern with two opened sides rather than the typical circular pattern. The rectangular pattern provides stability for the smoking wire mesh. Figure 2(c) shows the arrangement of the stones in a typical MTSF. Two or more of the MTSF can easily be put together by fish processors to enables them to run several batches at 


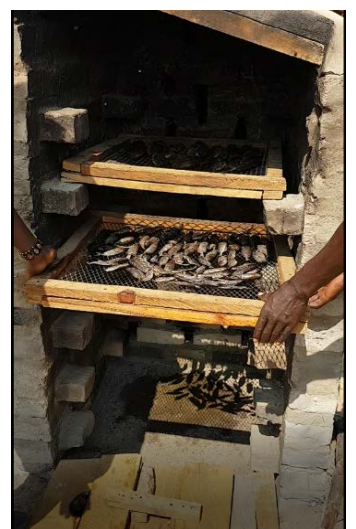

(a)

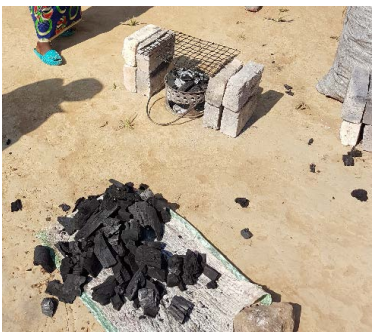

(b)

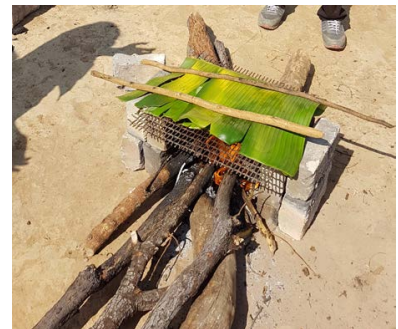

(c)

Figure 2. Pictures of fish processing systems (a) kiln (b) charcoal stove and (c) Modified Three-Stone-Fire (MTSF) stove.

a time depending on the number of drying and smoking wires owned by the processor. Although, TSF/MTSF is known to be inefficient with the efficiency of $10 \%-15 \%$ [8], has serious negative impacts on health and also significantly contributes to deforestation and regional climate change [5] [9], it is the most widely used smoking system. All the processors owned a traditional three-stone fire.

\subsubsection{Charcoal Processing Unit}

Fish processors also owned metal crafted coal-pot for burning charcoal. Not all processors owned the metal coal-pot but those who had them use them together with the MTSF. The different types of cook-stoves were not reserved primarily for use in the processing of fish but were used for almost all cooking applications within the household. Due to the cost of charcoal, the coalpot was not used to process fish but for other household activities. Its use has a wealth and social prestige associated and implies only individuals with high-income levels can purchase charcoal as fuel for use.

\subsubsection{Kiln}

The kiln shown in Figure 3 is a modified fish processing technique that has been recently introduced in the selected communities through participatory action research. The kiln was built with the involvement of community members. Low cost and locally available materials were selected for the construction of the kiln. For instance, metal trays (a square-meter mash wire costs about $25 \mathrm{Kwacha}$ ) and bricks were locally produced and sourced (each brick costs 2 Kwacha, about 300 bricks were used). Tray frames and doors were also made of wood (a plank costs 20 Kwacha, overall costs for wood were about 120 Kwacha) which is locally available and affordable. Although, it is not a community-wide option for fish processors, it has the potential of expanding the commercial fish processing business. The kiln is built with bricks having a height of $160-170 \mathrm{~cm}$ and a breath of $100 \mathrm{~cm}$. It is designed to have a smoking chamber where combustion of wood takes places. The smoke and heat from the combustion chamber flows into the main drying chamber through the $10-\mathrm{cm}$ perforated back wall. Flue gas 


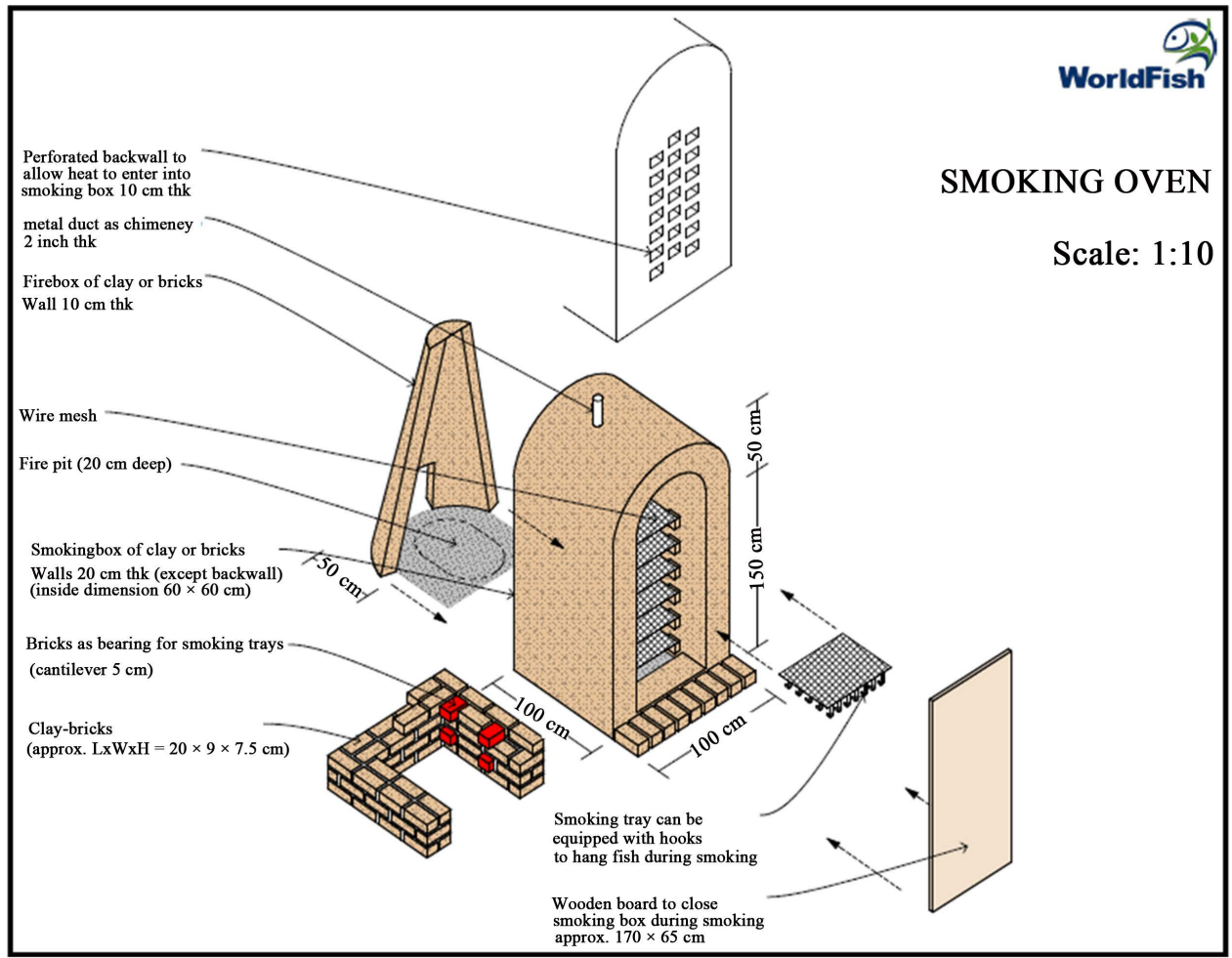

Figure 3. A schematic diagram of smoking kiln (source: worldfish).

from wood combustion passes through a 2 inches thick metal duct serving as a chimney. The kiln is also fitted with a wooden door which can be opened and closed easily. The kiln is designed to take six smoking trays. This is provided to hook and hang fish for ease of fat drop and improved heat and smoke circulation. The mildly dried fish is placed in the kiln after combustion commences. The trays are placed on $5 \mathrm{~cm}^{2}$ bricks on vertically aligned to either side of the Kiln's interior which allows them to be easily pulled out or slid in. The burning firewood supplies heat and smoke which dry the fish and preserve the fish [10]. The ashes and charcoal from the burnt wood remain at the based of the kiln and is removed afterward. The smoking kiln was set up to serve as a modified low-cost fish processing technique to aid in addressing the energy, health and environmental constraints associated with the traditional method of processing fish. It has additional benefits of improving the quality of fish and efficiency with fish processing.

\subsection{Fish Processing}

\subsubsection{Cleaning}

Cleaning is the first of the process. This involves the removal of scales from the skin of the fish and further cleaning. This is done manually with the use of a sharp knife and takes approximately 2 - 3 mins to descale a fish depending on size. The cleaning process also involves the removal of some internal constituents of the fish and thorough washing with warm or cold water. The cleaned fish can either be cooked immediately, sun-dried or smoked. 


\subsubsection{Pre-Smoking Drying}

When the processing method to be used is smoking, the cleaned fish pieces are dried on a drying wire using energy from the sun. The fish pieces are arranged in a single layer on the drying net and mounted diagonally on a pile of bricks to dry. The drying mesh is usually placed 60 to $100 \mathrm{~cm}$ above the ground. Depending on the amount of moisture content in the fish determined through touch and individual deductions, processors are able to decide on whether the fish is dried enough for further processing. Adequate drying of the fish is necessary to ensure that the moisture content is reduced to a minimal amount which is perceived to decrease the time and energy required for smoking. Drying also reduces the likelihood for the fish to stick to the wire when smoking. Drying takes approximately 20 to 35 mins for a minimum of one-kilogram Milonge (small fish) for 20 mins to $1 \mathrm{hr}$ for at least a kilogram of Tilapia (big fish) before smoking commences. The drying duration is largely dependent on the quantity of fish to be smoked. During the drying period, the fish is regularly turned to ensure uniform and adequate drying.

\subsubsection{Smoking}

Smoking generally takes approximately 1.5 to $3 \mathrm{hrs}$ per type and quantity of fish. Larger sized fish require a longer time for smoking compared to smaller sized fish. A minimum of 80 mins is required to smoke both small and large sized fish, however, a kilogram Milonge requires up to a maximum of 112 mins while a kilogram Tilapia requires at most 163 mins to adequately complete the process. The process of smoking though adds flavor to the fish, essentially to remove water from the fish through the application of heat with an outcome of water evaporation. Smoking begins immediately after the fish is dried for an appreciable amount of time. The drying wire with the moderately dried fish is transferred directly on to the smoking wire mesh on the heat source and covered with banana leaves to retain the heat and smoke which improves the flavor of the fish. Banana leaves also prevent flies from settling on the fish and enhances the color of the fish after smoking. The fish is turned intermittently at least once to ensure that all side of the fish is adequately smoked. The fish can either be smoked whole or after it has been cut into sizable portions. Smoking was terminated when there was a change in texture and color of the fish. The fuel is consistently monitored during the process and kept at a high level by supplying firewood or charcoal when needed to maintain heating levels.

A lot of attention is required during the smoking process to obtain good quality fish. Fish is directly in contact with the fire and thus continuous attention is required to prevent fish from burning. The tediousness of the activity is coupled with the need to collect wood to maintain fire and heat. Due to the small size of the drying wire used in smoking, the fish are usually smoked in batches when there is a large quantity of them in the situation where a three-stone process or charcoal process is being used. This results in difficulties of handling and processing large quantities of fish. The kiln, however, has the capacity to process 
much larger quantities of fish at the same time but is not yet in use. Smoking takes place in an open space when the charcoal stove or the three-stone firewood is used. The kiln is the only option where smoking is done in an enclosed space.

\subsubsection{Post-Smoking Drying}

The final process before the smoked fish is packaged for the market is drying. After smoking, the fish is also dried under the sun for about 5 hours for 2 to 5 days to ensure that the fish is completely dried and also to remove the heat from the smoked fish. Complete drying at this stage is necessary to remove moisture and prevent mold formation during storage. The fish is then stored in reed baskets, sacks or on raised shelves and sold either at the market or to individuals within the community. After the whole process of smoking is completed, it takes a minimum of 24 hours for the batch of smoked fish to be sold or a maximum of 2 months. The sale of smoked fish contributes to more than $50 \%$ of the monthly income of processors.

\subsection{Fish Processing Energy Consumption and Factors Affecting It}

\subsubsection{Heating Value of Fuel Used}

The heating value of the fuel used in fish processing was determined experimentally. The moisture content of the fuels was determined according to the ASABE Standard S358.2 by drying at $104^{\circ} \mathrm{C}$ for 24 hours in an oven (Fisher Scientific 750 , USA). The proximate analysis of wood and charcoal samples were determined thermogravimetrically using the standard test method for compositional analysis by thermogravimetry (ASTM E1131) [11]. Thermal analysis was carried out using thermogravimetric analyser Universal V4.7A TA Instruments (TGA Q500). Non-isothermal combustion was performed in the furnace of the thermobalance under controlled temperature. The dried wood was sampled for the TGA experiments. The wood samples $(20 \pm 0.5 \mathrm{mg})$ were combusted under oxidative environment in continuous airflow of $60 \mathrm{ml} / \mathrm{min}$ at a gauge pressure of $101 \mathrm{kPa}$ from room temperature to $850^{\circ} \mathrm{C}$ at $10^{\circ} \mathrm{C} / \mathrm{min}$. Analysis was conducted using the TA instruments Universal Analysis 2000 to determine the volatile matter (VM), fixed carbon (FC) and ash (ASH).

The heating value of the fuels expressed in $\mathrm{MJ} / \mathrm{kg}$ was estimated according to non-linear correlation proposed by [12].

$$
\begin{aligned}
\mathrm{HHV}= & 20.7999-0.3214 \frac{\mathrm{VM}}{\mathrm{FC}}+0.0051\left(\frac{\mathrm{VM}}{\mathrm{FC}}\right)^{2}-11.2277 \frac{\mathrm{ASH}}{\mathrm{VM}} \\
& +4.4953\left(\frac{\mathrm{ASH}}{\mathrm{VM}}\right)^{2}-0.7223\left(\frac{\mathrm{ASH}}{\mathrm{VM}}\right)^{3}+0.0383\left(\frac{\mathrm{ASH}}{\mathrm{VM}}\right)^{4} \\
& +0.0076 \frac{\mathrm{FC}}{\mathrm{ASH}}
\end{aligned}
$$

The thermal characteristics of the fuel used are shown in Table 2. Processors do not use a single fuelwood in smoking; therefore, an average heating value of the fuel used was estimated based on the four-main wood (Mpasa, Chimpampa, Mulombwa, and Muombo) types used in the communities. The average smoking 
Table 2. Wood species supplied for processing.

\begin{tabular}{cccccccc}
\hline \multirow{2}{*}{$\begin{array}{c}\text { Local wood } \\
\text { species }\end{array}$} & $\begin{array}{c}\text { Average Fraction } \\
\text { of pile (\%) }\end{array}$ & \multicolumn{4}{c}{ Proximate Analysis } & HHV \\
\cline { 3 - 6 } & 12 & Moisture & $V M$ & $F C$ & ASH & $(\mathrm{kJ} / \mathrm{kg})$ \\
\hline Mpasa & 6.5 & 77.5 & 13.6 & 2.4 & 18.83 \\
Chimpampa & 19 & 9.5 & 79.5 & 7.1 & 3.9 & 17.31 \\
Mulombwa & 23 & 8.8 & 75.6 & 10.2 & 5.4 & 17.93 \\
Muombo & 46 & 13.2 & 71.5 & 11.2 & 4.1 & 18.35 \\
\hline
\end{tabular}

fuel heating value was therefore calculated based on the fraction and heating value of a particular fuel according to Equation (2)

$$
\mathrm{HHV}_{\text {fuel }}=\frac{\sum_{i=1}^{i=4}\left(m_{i} \times \mathrm{HHV}_{i}\right)}{4}
$$

where $\mathrm{HHV}_{\text {fuel }}$ represent the heating value of the bulk fuel, $m_{i}$ and $\mathrm{HHV}_{i}$ represent the mass fraction and the heating value, respectively, of a wood species.

\subsubsection{Fish Processing Energy Consumption}

The specific fuel consumption of the different smoking systems is shown in Figure 4. The result shows that MTFS system consumes more fuel per kilogram of fish smoked. Comparatively, it uses more than $90 \%$ and $350 \%$ excess fuel than the kiln and the charcoal systems, respectively. A comparison of the mean fuel consumption reveals that there is a significant difference $(\mathrm{p}<0.05)$ among the three smoking systems.

The energy consumption per kilogram fish processed, shown in Figure 4, was estimated using an average wood fuel heating value of $18.11 \mathrm{~kJ} / \mathrm{kg}$ (calculated using Equation (2) and estimated dated data from Table 2) and charcoal heating value of $29.6 \mathrm{~kJ} / \mathrm{kg}$ (estimated thermogravimetrically). The result shows that specific energy consumption of the MTSF was at least $98 \%$ and $104 \%$ more than the kiln and the charcoal system, respectively. A comparison of mean energy consumption using the Turkey-Kramer HSD model indicates that there was no significant difference between the kiln and the charcoal stove, although, the amount of fuel used in the kiln was significantly higher. This seemly similar energy consumption may be due to the higher heating value of charcoal $(63 \%$ higher). Although the kiln and TSF use wood as the fuel, the wide margin observed in their energy consumption may be attributed to the systems' capacity. The kiln at full capacity can process at least five times more fish than the MTSF system. During the experiments, three times more fish was processed with the kiln at a capacity of $50 \%$ (three shelves) than with the MTSF. Thus, a wider margin in energy consumption between both systems which was calculated per kilogram of fish is expected since the quantity of fish processed in the kiln is significantly higher compared to the MTSF. 


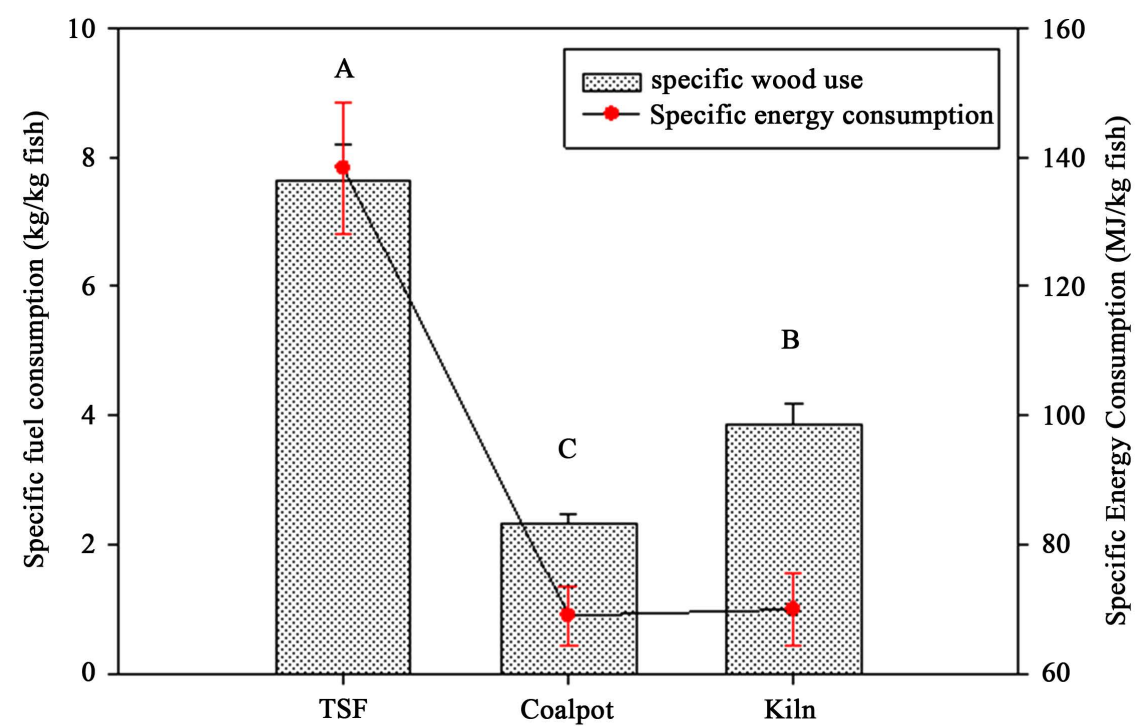

Figure 4. Specific wood and energy consumption for different fish processing systems.

Although, the result shows the energy requirement of the charcoal system is the least it may not be the most popular option primarily due to cost. Unlike wood which is collected by the processors from the farms at no cost, charcoal is bought from other sellers, therefore, increasing the total cost of production and minimizing the profit.

\subsubsection{Effect of Fish Type on Energy Consumption}

The type of fish processed was also evaluated to ascertain its effect on energy consumption. Two types of fish were smoked using the three fish smoking systems. Figure 5 shows the effect of the fish type on energy consumption. Considering the fact that it takes $13-19$ min less to smoke the small fish, one would expect more energy to be used for smoking tilapia, however, this was not the case. The results show that irrespective of the system used, smoking Tilapia uses less energy per kilogram fish compared to the Milonge. The difference was, however, not statistically significant for the charcoal system. The variation was marked in the MTSF system showing up to $18.5 \%$ more energy required for smoking Milonge fish. This difference in energy consumption may be attributed to the weight variant of the fish and smoking capacity of each system. A completely filled smoking wire net could contain $6.6 \mathrm{~kg}$ of Tilapia compared to 5.7 $\mathrm{kg}$ of Milonge. Therefore, for the same amount of fuel used in smoking, the energy per $\mathrm{kg}$ of fish is expected to less for the tilapia. In the kiln, the variation is expected to widen because even at $50 \%$ capacity ( $19.8 \mathrm{~kg}$ of tilapia), it could take up to $2.7 \mathrm{~kg}$ more of tilapia.

\subsubsection{Fish Processing Duration}

Prior to smoking, the fish is dried in the sun to drain water and other fluid from the fish. The impact of this pre-smoking drying on fuel and energy consumption was evaluated. Figure 6 shows the average fish processing duration at different 


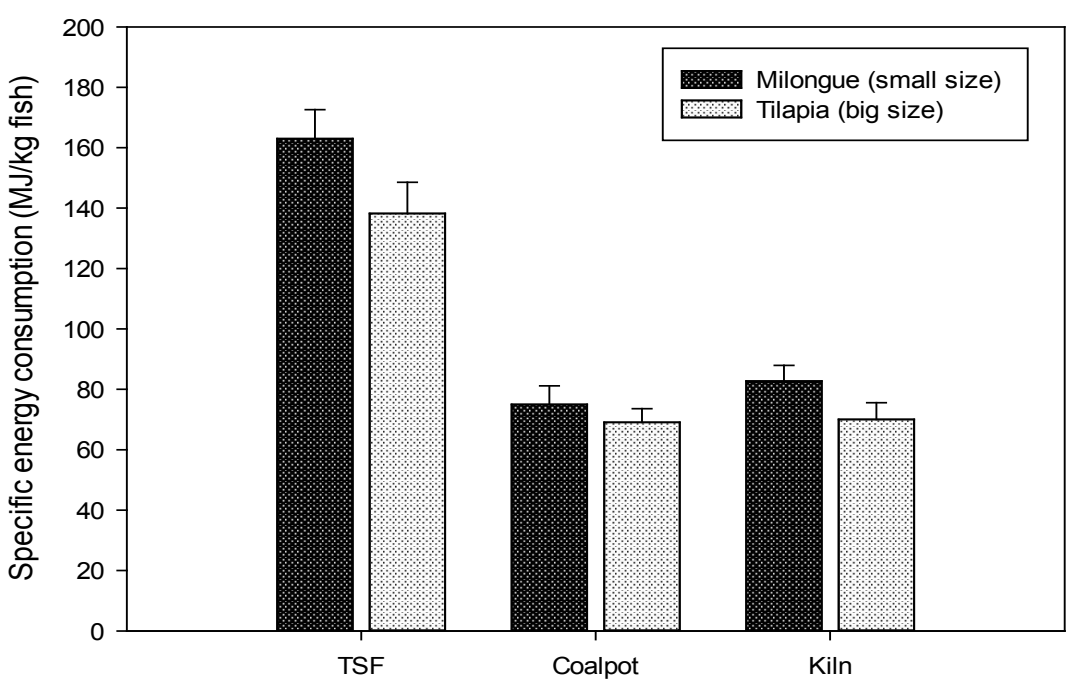

Figure 5. Effect of fish type on specific energy consumption for different fish processing systems.

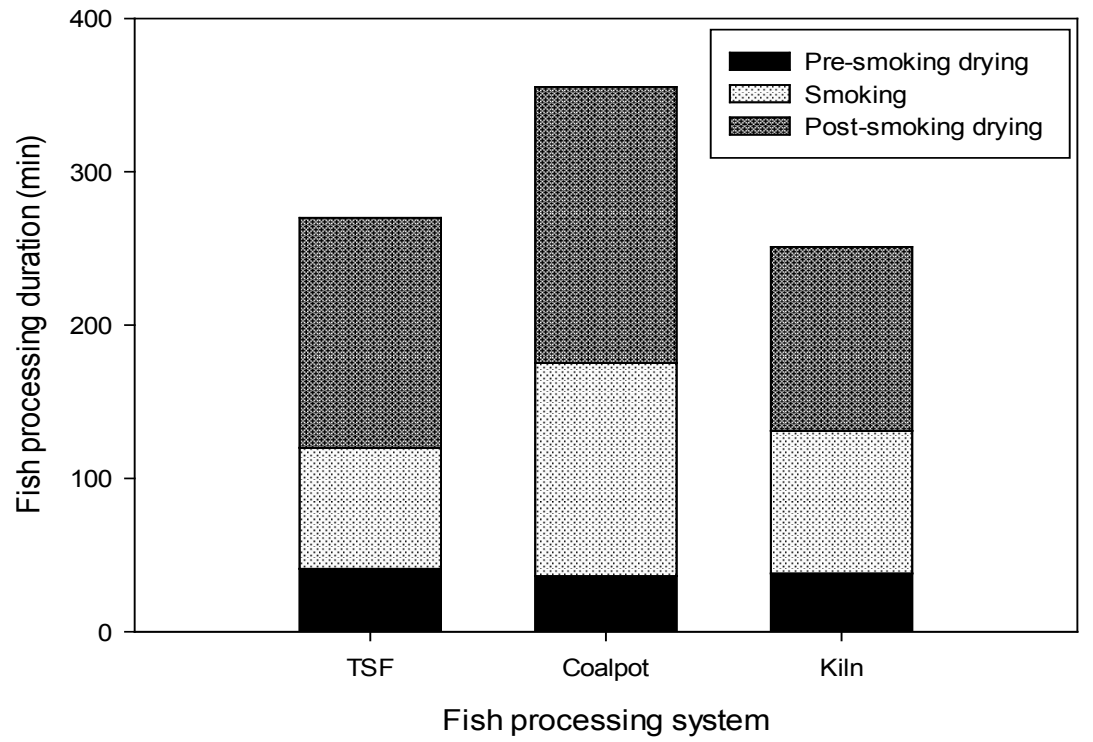

Figure 6. Average duration for different fish processing systems.

stages. The average pre-smoking drying time was $38 \pm 5 \mathrm{~min}$ for tilapia and $31 \pm$ $6 \mathrm{~min}$ for Milonge. The smoking time varied significantly among the different smoking systems with the charcoal system using the most time of up to $139 \mathrm{~min}$ per batch of $3.6 \mathrm{~kg}$ and the kiln the least time. The post-smoking drying time ranged from 122 to $176 \mathrm{~min}$. This duration, however, was not affected by the smoking system but the size and type of fish. A drying tray containing larger fish with an average post-smoking weight of $0.3-0.47 \mathrm{~kg} /$ fish were dried for up to 176 min while smaller size fish with a post-smoking weight of less than 0.06 $0.09 \mathrm{~kg} /$ fish were dried up to $134 \mathrm{~min}$. Considering the quantity of fish processed operating the kiln at $50 \%$ capacity would result in a reduction of the $39 \%$ of the overall processing time. At higher capacity, the time gained will further increase. 
Figure 7 shows the impact of the pre-smoking drying time on energy consumption. The result shows that pre-smoking drying time influences the energy consumption regardless of the smoking system. As can be seen from the graph, pre-smoking drying for only 20 min could significantly increase the energy consumption up to $21 \%$. Another noticeable detail is that beyond $30 \mathrm{~min}$ of pre-drying, there is no significant difference in energy consumption. This implies that processors do not gain on fuel by extending the pre-smoking drying time as is presumed.

\subsubsection{Modelling Factors Affecting Fish Processing Energy Consumption} Table 3 presents prediction models for fish smoking fuel consumption. The models have been developed taking into account the two main factors affecting fuel consumption-the amount of fish being processed and the pre-smoking drying time. Other factors such as fish type and size were not considered due to the potential large variability within the study communities. For the MTSF system, an exponential model give a better fit with higher $\mathrm{R}^{2}$ than the linear model. This implies up to $91 \%$ of the variability can be explained by the model. The kiln, on the other hand, gave a higher $\mathrm{R}^{2}$ for a linear model. The effect of the pre-smoking drying time was also considered in the models. The inclusion of the drying time slightly improved the models, especially for the kiln.

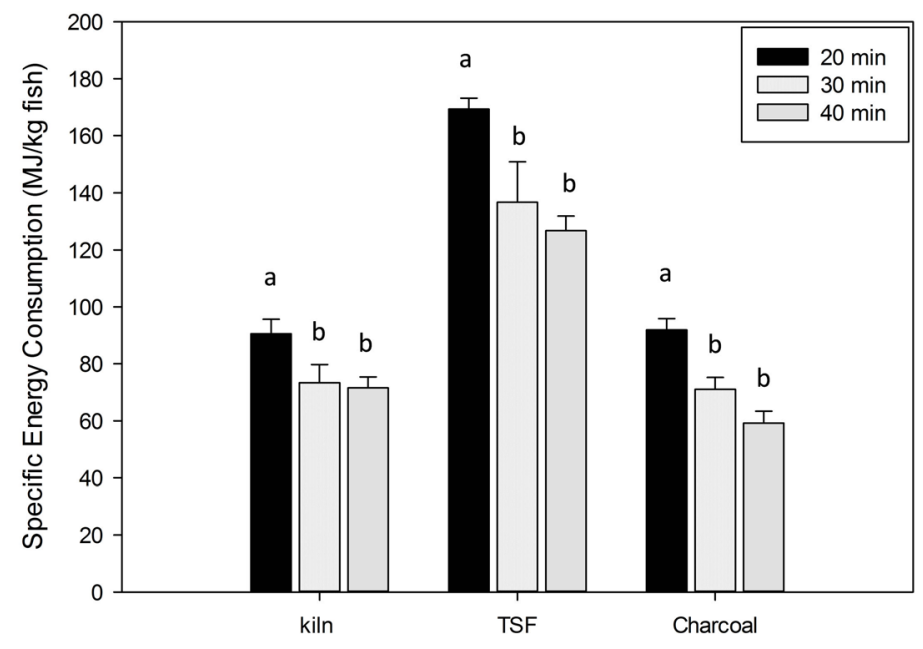

Figure 7. Effect of pre-smoking drying time on specific energy consumption.

Table 3. Prediction of wood consumption for fish processing.

\begin{tabular}{cccc}
\hline System & Factor & Model & $\mathbf{R}^{2}$ \\
\hline \multirow{2}{*}{ TSF } & Fish weight & $y=3.06+1.11 x$ & 0.704 \\
& Fish weight & $y=4.142\left(1-0.011^{x}\right)$ & 0.919 \\
& Fish weight, pre-smoking drying time & $y=3.09+1.20 x-0.002 d$ & 0.705 \\
\multirow{2}{*}{ Kiln } & Fish weight & $y=0.34+0.09 x$ & 0.970 \\
& Fish weight, pre-smoking drying time & $y=0.47+0.04 x+0.009 d$ & 0.998 \\
\hline
\end{tabular}

$\mathrm{x}$ and $\mathrm{d}$ represent fish weight and pre-smoking drying time, respectively. 


\subsection{Socioeconomic and Environmental Implications of Current Fish Processing Systems}

The energy dynamics of fish processing systems have huge socioeconomic and environmental implications. These are often woven into a complex energy-cost-quality nexus which in most cases are not given attention. For instance, the reliability of energy supply, energy cost and indirect factors such as health and environmental effects will certainly influence the dynamics of selecting a system even if it decreases quality and nutrient. This section examines the dynamics from a cost, quality and health and environmental perspectives.

\subsubsection{Cost}

Energy supply is the driving force of fish processing and will always come at a cost and will influence the choice of system employed. The cost may be expressed in monetary terms as in the cost of charcoal or in human energy cost as in monetary equivalent of the time and energy spent in collecting wood. More than $90 \%$ of energy is collected from wood collection points when firewood is being used. Firewood availability for fish processing continuously pose a challenge not only because of long distance travel but more importantly the increase in human energy cost as the forest depletion further increases. During raining seasons, the challenge of drying the wood compounds the overall human energy cost. Charcoal use, on the other hand, as a monetary cost which makes a costlier option irrespective of its availability and reliability since it increases the cost of fish processing. Any delays and unavailability of fuel may lead to an unreliable energy supply and will have the potential to considerably reduce the rate of fish processing and overall productivity.

\subsubsection{Social, Health and Environment Implications}

The collection and use of firewood for fish processing are not particularly desired by many households but fish smoked with firewood do have distinct flavor which is widely desired by consumers. Households which use charcoal for food preparation and fish processing are perceived to be of a high social standing due to the fact that only households with higher income levels are able to purchase it. In spite of this, very few processors use charcoal as a source of fuel for fish processing and less frequently due to the lack of income to purchase charcoal. The choice of fuel affects the total processing cost which reduces profits and income. Again, firewood collection is time and energy consuming. The collection time reduces the time for other productive activities some of which can be income generating activities and thus can be costly to households. It also has the potential of keeping children out of school which present a huge social implication.

In addition to the social cost, the use of wood as a source of fuel for the processing has negative health implications. Due to the unavailability and inaccessibility of efficient cooking technologies by rural households in low-income communities like those selected for this study, the most common method of 
cooking is with the use of wood and/or charcoal. Fish processors within the communities constitute part of the estimated 3 billion people who have been found by [13] to cook with solid fuels in open fires around the world. The combustion of the wood fuels releases small particles and other pollutants that are emitted into the surrounding environment. These pollutants when inhaled could block the airways and lungs, limiting the capacity of the blood to carry oxygen to different parts of the body hindering immune response with an evidence of related diseases [13]. Open fires, simple stoves and the use of charcoal in the processing of food have been estimated to account for the premature deaths of over 4 million people due to household air pollution from the burning of solid fuels. A substantial percentage $(>50 \%)$ of deaths among children under 5 years have been attributed to the inhalation of matter from the burning of biomass and coal which causes diseases such as pneumonia. Other diseases attributable to household air pollution are stroke, ischaemic heart disease, chronic obstructive pulmonary disease and lung cancer, with stroke (34\%) accounting to a greater percentage of deaths followed by ischaemic heart disease (26\%) [13].

Fish processing in the community is mainly undertaken by women which implies that exposure to household air pollution is higher among women compared to men. This corroborated with [13] findings that women and children are more exposed to the release of health-damaging pollutants from the use of solid fuels because they spend more time around cooking fires [14]. Women are particularly 2.3 times more likely to suffer from chronic obstructive pulmonary disease when exposed to indoor smoke from solid fuels compared to the use of cleaner fuels. Firewood use does not only pose a cost to health only through the emission of pollutants but also risks to physical injury during wood collection and transportation. The traditional stoves also contribute to bums, cuts, and scalds [2] [3] [4]. Sickness from household air pollution reduces the capacity of processors to perform activities and derive a substantial livelihood from it.

The emissions which result due to inefficient combustion of the firewood and charcoal has a significant effect on climate change since the methane and black carbon released are climate change pollutants [13]. Many households rely on firewood as a source of fuel which creates a problem of deforestation as trees are cut down to meet fuel demand. Firewood will not be a source of sustainable energy option due to the higher rate of deforestation as against the lower rate of replanting of trees.

Though each of the fish processing systems is not very efficient in the combustion of solid fuel, there is a significant difference in the efficiencies of the systems used in the communities. The use of the three-stone processing system doesn't only release a greater amount of smoke and soot which fill up the immediate surroundings of the processors affecting their health, but it has a negative social stigma attached to it. Although the kiln uses firewood as its source of fuel has been designed to be a closed system where its smoke is directed towards the sky and thus away from the individuals' operation the system. In comparison 
with the other processing systems, it will have a much higher social status attached to it but is not a current practice within the community. The charcoal processing system, on the other hand, has very little emissions during the processing of fish and thus much safer and healthier than the use of firewood. Due to this, as well as the limited time in obtaining it and the requirement of income for purchase, it has a positive social status attached to it. Both firewood and charcoal have an adverse effect on the environment and climate change since they are obtained from the cutting and burning of wood. The relative social, health and environmental effect of each processing systems, however, differ, with one, providing a slight advantage over another in different aspects. Interventions such as improvement of fish processing systems and energy sources have the likelihood of improving the lives of processors and the environment.

\subsubsection{Quality and Willingness to Pay Analysis}

A survey was undertaken to determine processors preference for the three fish processing systems, the factor(s) influencing their choice as well as the amount they are willing to sell for fish smoked in the most preferred choice of system. Processors were individually asked to determine the most preferred choice of system to the least by ranking on a scale of 1 (least preferred) to 5 (most preferred). After ranking, they were required to provide the reason for their most preferred choice. Based on the information gathered, it was found that all the interviewed processors ranked the kiln as the most preferred fish processing system because the fish had an attractive color after processing in the kiln. Another reason provided was that the fish dried more adequately when the kiln was used. Three stone fire processing system was the ranked as the second most preferred system with the charcoal processing system being the least preferred. The MTSF processing system was ranked second because of the kind of fuel used which is firewood. It was much less desirable due to the emissions and safety risk involved with direct contact with the fire. The use of firewood has been found to give the fish a distinct flavor which is widely desired by consumers and thus commands a good price compared to fish smoked with charcoal. The type of fuel for the kiln is firewood which gives the fish the same distinct flavor including other benefits. This explains the factors influencing the ranking of the different processing systems.

The use of a kiln in processing fish is not a common practice in the community, all the processors used the three- stone processing system in processing fish while a few others occasionally used the charcoal processing system. Since the kiln was a new processing system within the community, the survey proceeded to determine the amount farmers are willing to sell fish processed with the kiln and how much they would have purchased it if sold to them. The average price of smoked fish (large sized Tilapia) is K16 per piece however, the survey showed that the processors were willing to sell fish processed in the kiln for more than that price because it was of more quality than fish processed with other systems. 
Majority of the respondents were willing to sell fish for K20 which is K4 more than the current price. The highest amount processors are willing to sell the fish was for K25. The use of kiln as a processing system has the advantage of ensuring that much larger quantities of fish are processed at the same. This does not only reduce the amount of processing time thus increasing productivity but it also likely to command a higher price on the market.

Soliciting willing to pay information from the processors provides an indication of how much consumers will be purchase fish processed with the kiln. Though all the processors were willing to sell the smoked fish at a price higher than the current price, the majority of them were willing to purchase the fish at a lesser price than they are willing to sell. The respondents were, however, willing to purchase the smoked fish at K20 or less. Majority of the respondents were willing to purchase the fish at $\mathrm{K} 10$ or less rather than at a higher price. Nevertheless, the processors would still be able to have a higher price for fish processed with the kiln than with the MTSF or charcoal system.

\section{Conclusion}

In this study, local fish processing activities and their impact on energy consumption for three processing systems were discussed. Field measurement of local fish processing energy use in two communities in the Northern Province of Zambia provided the data for the analysis. Fish smoking is the dominant form of fish processing in the selected communities with wood as the primary source of fuel. The duration of wood collection, smoking and drying are the major activities and require a significant amount of time for their execution. The wood collection takes approximately one to 1.5 hours while smoking takes 1.5 to $3 \mathrm{hrs}$ for per type and quantity of fish. The processing system mainly used is the modified three-stone fire stove. Compared to the kiln and the charcoal stove, the energy consumption of the MTSF was found to be at least $98 \%$ and $104 \%$ more, respectively. Other factors affecting fish smoking energy consumption are the pre-smoking drying time. Drying for $20 \mathrm{~min}$ or less prior to smoking could significantly increase the energy consumption up to $21 \%$, but beyond 30 mins would not result in any further significant reduction in energy consumption. The type of fish was also found to influence energy consumption, with Tilapia using less energy per kilogram fish compared to the Milonga due to weight variant of the fish and smoking capacity of the MTSF. The results of the study provide very useful information which can aid stakeholders and policymakers in designing developmental goals related to fish processing and its energy requirements. Since it serves as a source of income for a substantial number of individual and has a high demand due to its nutritional value, improvements in this stage of the value chain can be economically and socially beneficial. The study recommends the use of the kiln for improved processing since it consumes less energy, has the likely to improve productivity, fish quality, and profitability and has the potential of reducing the health risks. 


\section{Acknowledgements}

The authors gratefully acknowledge the International Fund for Agricultural Development (IFAD) for providing financial assistance through IFAD project grant 2000000974

\section{Conflicts of Interest}

The authors declare no conflicts of interest regarding the publication of this paper.

\section{References}

[1] FAO (2006) Zambia Fishery Country Profile. Food and Agriculture Organization of the United Nations, Roma.

[2] Desai, M.A., Mehta, S. and Smith, K.R. (2004) Indoor Smoke from Solid Fuels: Assessing the Environmental Burden of Disease at National and Local Levels. WHO Environmental Burden of Disease Series No. 4, World Health Organization, Geneva.

[3] Johnson, N.G. (2005) Risk Analysis and Safety Evaluation of Household Stoves in Developing Nations.

[4] Wickramasinghe, A. (2003) Gender and Health Issues in the Biomass Energy Cycle: Impediments to Sustainable Development. Energy for Sustainable Development, 7, 51-61. https://doi.org/10.1016/S0973-0826(08)60365-8

[5] Ramanathan, V. and Carmichael, G. (2008) Global and Regional Climate Changes Due to Black Carbon. Nature Geoscience, 1, 221-227. https://doi.org/10.1038/ngeo156

[6] Lim, J.S., Abdul Manan, Z., Wan Alwi, S.R. and Hashim, H. (2012) A Review on Utilization of Biomass from Rice Industry as a Source of Renewable Energy. Renewable and Sustainable Energy Reviews, 16, 3084-3094. https://doi.org/10.1016/j.rser.2012.02.051

[7] CSO (2010) Census of Population and Housing. National Descriptive Tables, Vol. 11, Central Statistics Office, Lusaka.

[8] Bhattacharya, S.C., Albina, D.O. and Abdul Salam, P. (2002) Emission Factors of Wood and Charcoal-Fired Cookstoves. Biomass and Bioenergy, 23, 453-469. https://doi.org/10.1016/S0961-9534(02)00072-7

[9] Bond, T. and Sun, H. (2005) Can Reducing Black Carbon Emissions Counteract Global Warming? Environmental Science \& Technology, 39, 5921-5926. https://doi.org/10.1021/es0480421

[10] Adamu, I.G., Kabri, H.U., Hussaini, I.D. and Mada, A.D. (2013) Design and Construction of Smoking Kiln. Journal of Engineering and Technology Research, 5 , 15-20. https://doi.org/10.5897/JETR12.042

[11] ASTM (2010) Standard E1131-08. In: Test Method for Compositional Analysis by Thermogravimetry, American Society for Testing and Materials, West Conshohocken, 17.

[12] Nhuchhen, D.R. and Abdul Salam, P. (2012) Estimation of Higher Heating Value of Biomass from the Proximate Analysis: A New Approach. Fuel, 99, 55-63.

https://doi.org/10.1016/j.fuel.2012.04.015 
[13] WHO (2014) Household Air Pollution and Health. World Health Organization, Geneva.

[14] Bruce, N., Perez-Padilla, R. and Albalak, R. (2000) Indoor Air Pollution in Developing Countries: A Major Environmental and Public Health Challenge. Bulletin of the World Health Organization, 78, 1078-1092. 